\title{
BLAIR BELL RESEARCH SOCIETY SYMPOSIUM
}

\section{A Symposium on Myometrial Contractility and its Regulation}

Held at the Royal College of Obstetricians and Gynaecologists, London, on 16 May 1968

Editors

\section{BRENDA M. SCHOFIELD Ph.D., D.Sc.}

Professor A. C. TURnbull M.D., F.R.C.O.G.
The luteo-placental shift, the guardian of pre-natal life

Evidence of a foetal role in determining the length of gestation

The importance of progesterone in the maintenance of pregnancy in the sheep

Studies in the regulation of uterine activity

Experiments on the control of myometrial activity in the non-pregnant woman

The effect of an intra-uterine device on uterine motility in women and rhesus monkeys

The distribution of cholinergic and other nerve fibres in the human uterus
Arpad Csapo

A. C. Turnbull and ANNE B. M. ANDERSON

Brenda M. Schofield

D. G. Porter

Lars Philip Bengtsson

J. H. Marston, W. A. Kelly and P. ECKsTEIN

R. E. Coupland

The Editors and the Council of the Fellowship of Postgraduate Medicine gratefully acknowledge the assistance of Sandoz Products Limited in the organization and publication of this Symposium 